\title{
Tarsal tunnel syndrome and peripheral neuropathy in rheumatoid disease
}

\author{
LOUIS McGUIGAN, ${ }^{1}$ DAVID BURKE, ${ }^{2}$ AND ANTHONY FLEMING ${ }^{1}$ \\ From the Departments of ${ }^{1}$ Rheumatology and ${ }^{2}$ Neurology, the Prince Henry Hospital, Sydney 2036, Australia
}

SUMMARY Thirty patients with classical or definite rheumatoid disease (RD) with foot pain and radiologically demonstrated erosions were studied electrodiagnostically to ascertain the frequency of the tarsal tunnel syndrome and peripheral neuropathy. Four patients $(13 \cdot 3 \%)$ had evidence of the tarsal tunnel syndrome. The electrical abnormalities were mild and unassociated with specific clinical features. Two patients $(6 \cdot 6 \%)$ had evidence of sensory peripheral neuropathy. There may be an appreciable frequency of clinically unsuspected tarsal tunnel syndrome in RD.

The principal neuropathies of rheumatoid disease (RD) include nerve compression, a mild distal sensory impairment, and a severe fulminating sensorimotor disorder. ${ }^{1}$ Unlike the sensorimotor disorder, which is easily recognised, ${ }^{2}$ the compression and distal sensory neuropathies may be manifest only by paraesthesiae, dysaesthesiae, and burning sensations, with few objective signs. ${ }^{34}$

Median nerve entrapment in the carpal tunnel is common in RD and has been well documented clinically and electrodiagnostically. ${ }^{5}$ However, while entrapment at the tarsal tunnel has been implicated as contributing to foot pain in $\mathrm{RD},{ }^{67}$ the importance of this complication is unknown owing to the lack of systematic electrodiagnostic studies. Recently other investigators ${ }^{8}$ using these techniques reported a $25 \%$ frequency of tarsal tunnel syndrome in RD, but the failure to correct for temperature variations in their patients could have given a falsely high result.

The frequency of distal sensory neuropathy in RD is undetermined, although estimates have put it as high as $35-40 \%$. $^{4}$ The relevance of most previous studies of peripheral polyneuropathy in RD is in doubt, as most have examined only motor conduction, often in the upper limbs or in nerves that can themselves be the subject of entrapment. ${ }^{9-13}$ However, acquired peripheral polyneuropathies in adults are almost invariably more severe in the lower limbs and usually affect sensory conduction more than motor. ${ }^{14}$ There has been no systematic study of sensory conduction in the lower limbs of patients with RD.

Accepted for publication 25 February 1982.

Correspondence to Dr A. Fleming, Department of Rheumatology, The Prince Henry Hospital, Little Bay, NSW 2036, Australia.
We investigated 30 patients with classical or definite RD who had both pain and erosions in the feet, and we sought clinical and electrical evidence of peripheral polyneuropathy or tarsal tunnel syndrome in order to assess their frequency and to determine whether they contribute to the foot pain of RD.

\section{Patients and methods}

\section{PATIENTS}

Thirty patients with classical or definite $\mathrm{RD}^{15}$ were studied. All were seropositive to the rheumatoid factor and had foot pain and radiologically demonstrated erosions in the feet. Patients who had undergone foot surgery or who were over 65 years of age were excluded. None of the patients were diabetic, but 5 consumed more than $100 \mathrm{~g}$ of alcohol per day. The mean age of the selected group was $50 \cdot 9$ years (range 24-65). The mean disease duration was 9.9 years (range $1 \cdot 5-26 \cdot 0$ ). In 12 patients the disease was active. All 30 patients were taking nonsteroidal anti-inflammatory agents. Six patients were on prednisone and 24 were on a slow-acting disease suppressive agent.

\section{METHODS}

A detailed history and clinical examination including neurological examination was performed on each patient. The compound muscle action potentials of the abductor hallucis muscle (medial plantar nerve) and the abductor digiti quinti muscle (lateral plantar nerve) were evoked by stimulation of the posterior tibial nerve behind the medial malleolus and were recorded with pairs of surface electrodes fixed over the muscles in standard positions, as described by 
Johnson and Ortiz ${ }^{16}$ and Fu et al. ${ }^{17}$ (Fig. 1). The stimulating electrodes were secured to the limb with the cathode distal, either $80 \mathrm{~mm}$ or $100 \mathrm{~mm}$ from the active recording electrode on the motor point of abductor hallucis. ${ }^{17}$ The amplitude of the negative phase of each evoked compound action potential and the latency of onset of the negative phase were calculated. Skin temperatures were measured with a thermistor, as described by Fu et al. ${ }^{17}$ and the motor latencies were then compared with established normal values for conduction distance $(80 \mathrm{~mm}$ or 100 $\mathrm{mm}$ ) and skin temperature. ${ }^{17}$ The conduction velocity of motor fibres innervating abductor hallucis for the popliteal fossa-ankle segment was determined by standard techniques (Fig. 1), the lower limit of normal for this laboratory being $40 \mathrm{~m} / \mathrm{s}$.

Sensory conduction was studied in the medial plantar nerve and in 2 segments of the sural nerve by surface-stimulating and recording techniques (Fig. 2). The orthodromic sensory action potential of the medial plantar nerve was recorded at ankle level by a pair of $\mathrm{Ag} / \mathrm{AgCl}$ electrodes $40 \mathrm{~mm}$ apart, after stimulation of the digital nerves of the hallux by ring electrodes. ${ }^{18}$ Similar pairs of recording electrodes at the
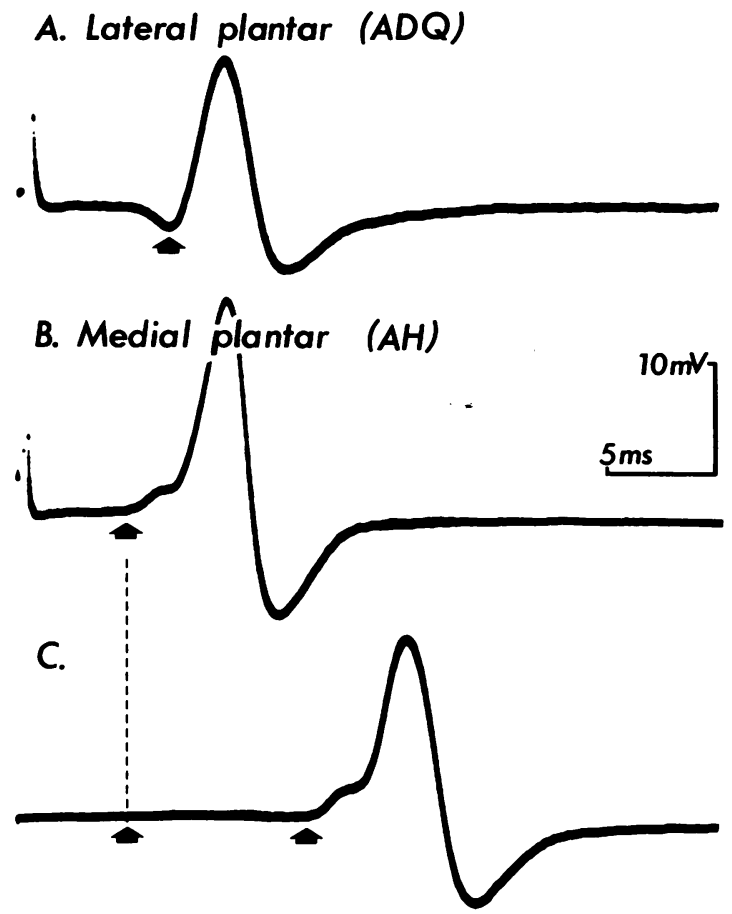

Fig. 1 Motor conduction. Compound muscle action potentials at the ankle (A and $\mathrm{B})$ and at the popliteal fossa (C).
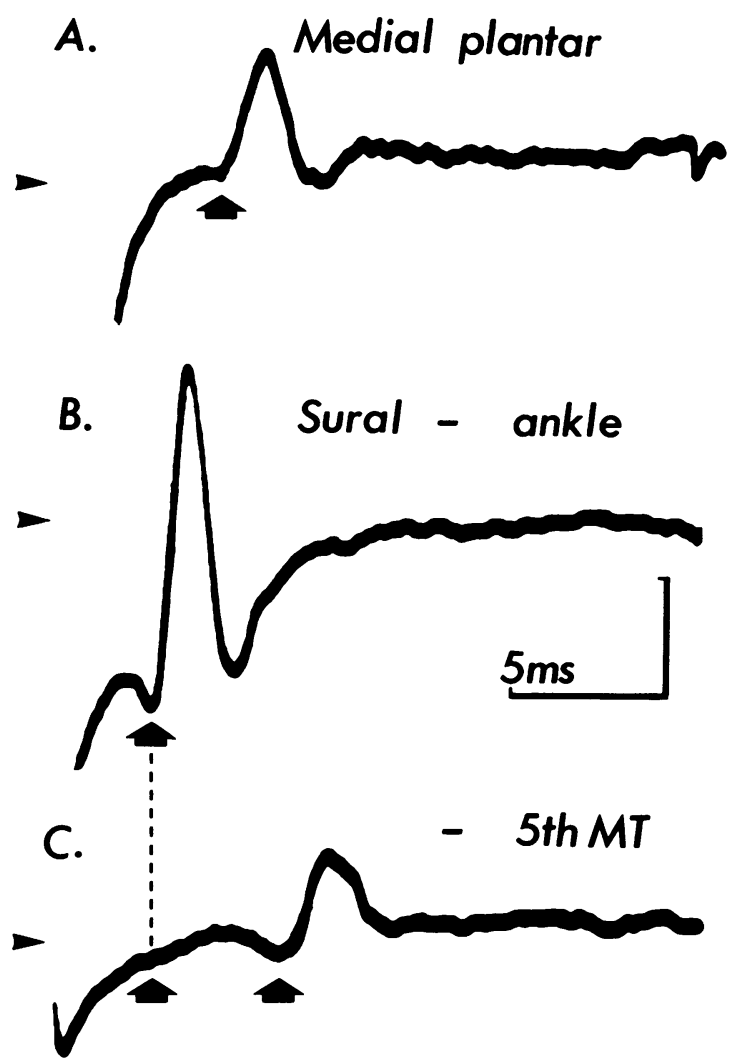

Fig. 2 Sensory conduction of the medial plantar and sural nerves. The conduction time for distal segment of the sural nerve (ankle-fifth metatarsal $(M T)$ ) is the time between the vertical arrows in $\mathrm{C}$.

lateral malleolus and at the fifth metatarsal recorded the antidromic sensory action potential set up in the sural nerve by stimulation of the nerve at mid-calf level. The segments of the sural nerve thus studied were calf-ankle and ankle-fifth metatarsal. The laboratory lower limits of normal are $6 \mu \mathrm{v}$ and $40 \mathrm{~m} / \mathrm{s}$ for the proximal segment (calf-ankle) of the sural nerve, and $35 \mathrm{~m} / \mathrm{s}$ for the distal segment (ankle-fifth metatarsal) and for the medial plantar nerve.

Appropriate measurements of skin temperature were made with a thermistor. Conduction velocities were corrected to $32^{\circ} \mathrm{C}$ by factors of $1.5 \mathrm{~m} / \mathrm{s} /{ }^{\circ} \mathrm{C}$ for proximal nerve segments and $2.2 \mathrm{~m} / \mathrm{s} /{ }^{\circ} \mathrm{C}$ for distal sensory nerve segments. ${ }^{19}$

\section{CRITERIA FOR DIAGNOSIS}

The tarsal tunnel syndrome was diagnosed if the distal motor latencies to abductor hallucis (medial plantar nerve) or to abductor digiti quinti (lateral plantar nerve) or both were prolonged beyond 2 standard 
deviations (SD) from the normal mean for temperature and conduction distance. ${ }^{17}$ Abnormalities of muscle action potential amplitude and of medial plantar sensory conduction were considered supportive evidence for this diagnosis.

Sensory polyneuropathy was diagnosed if the temperature-corrected sensory conduction velocities were below the laboratory's lower limit of normal (see above) or if the sensory action potential of the proximal segment of the sural nerve was below $6 \mu \mathrm{v}$.

\section{Results}

\section{L I N I C A L}

Although all patients complained of pain in the feet, often of a burning character, only 3 gave a history of numbness or paraesthesiae. One of these patients had no clinical abnormality. The second had demonstrable sensory loss confined to an area over the base of the third toe on the left foot. The third had hyporesponsive ankle jerks.

\section{E LE C T R I C A L}

Four patients ( 3 males, 1 female) satisfied the criteria for the tarsal tunnel syndrome. Of these one showed slowing of the medial plantar nerve latency only, one slowing of the lateral plantar nerve latency only, and 2 slowing of both (Table 1 ). In addition all 4 had no demonstrable medial plantar sensory potential, which supports the diagnosis of tarsal tunnel syndrome (Table 2). There was no relationship to disease activity. The electrical abnormalities were not gross, with no motor latency delayed beyond 3 standard deviations from the mean. In none of the $\mathbf{3 0}$ patients were the amplitudes of either compound muscle action potential more than 2 standard devia- tions below the normal mean. ${ }^{20}$ In 3 of the 4 patients with tarsal tunnel syndrome the appropriate muscle action potentials were between 1 and 2 standard deviations below the normal mean, and were the lowest-amplitude potentials recorded in this study. In all 30 patients the motor conduction velocity of the posterior tibial nerve was within normal limits.

Two patients, both males, had evidence of peripheral sensory polyneuropathy. The abnormalities in these 2 patients were pathologically low sensory potentials ${ }^{15}$ in the proximal segment of the sural nerve ( $4 \mu \mathrm{v}$ in both cases), absent medial plantar sensory potentials, and absent or abnormal distal sural sensory potentials. In both patients proximal sural and posterior tibial conduction velocities were within normal range ${ }^{1215}$ (Table 2). Only one of these 2 patients had any clinical abnormality, described above as hyporesponsive ankle jerks. Apart from those patients with the tarsal tunnel syndrome and sensory polyneuropathy there were 3 others in whom a medial plantar sensory potential was unobtainable. These patients had no other electrical or clinical abnormality. Their ages were 59,60 , and 60 years. In this age range normal controls may not have a demonstrable medial plantar sensory potential. ${ }^{18}$

A normal distal sural sensory potential could be obtained in $23(77 \%)$ patients. In them it was a further indication that there was no significant sensory polyneuropathy. Two of the remaining 7 patients had proximal sural abnormalities as described above: in one no distal sural potential could be recorded; in the other the potential was of low amplitude $(0.5 \mu \mathrm{v})$ and slow conduction velocity $(34.4 \mathrm{~m} / \mathrm{s}$ after temperature correction). The remaining 5 patients had no other evidence of disease. The distal sural sensory potential is often difficult to

Table 1 Motor latencies across tarsal tunnel

\begin{tabular}{lllll}
\hline Motor latency & $\begin{array}{l}\text { Number of latencies } \\
\text { obtained }\end{array}$ & $\begin{array}{l}\text { Uncorrected latencies } \\
\text { range }(\mathrm{ms})\end{array}$ & $\begin{array}{l}\text { Temperature range } \\
\left({ }^{\circ} \mathrm{C}\right)\end{array}$ & $\begin{array}{l}\text { Corrected latencies }>2 \text { SD } \\
\text { from mean }\end{array}$ \\
\hline Medial plantar & 30 & $3 \cdot 5-5 \cdot 9$ & $25-33^{\circ}$ & 3 \\
Lateral plantar & 30 & $4 \cdot 4-7 \cdot 5$ & $24-33^{\circ}$ & 3 \\
\hline
\end{tabular}

Table 2 Results of peripheral nerve conduction

\begin{tabular}{|c|c|c|c|c|c|c|c|}
\hline \multirow[t]{2}{*}{ Nerve } & \multirow[t]{2}{*}{$\begin{array}{l}\text { Number } \\
\text { recorded }\end{array}$} & \multicolumn{2}{|c|}{ Amplitude $\mu \nu$} & \multicolumn{2}{|c|}{$\begin{array}{l}\text { Uncorrected conduction } \\
\text { velocity }(\mathrm{m} / \mathrm{s})\end{array}$} & \multicolumn{2}{|c|}{$\begin{array}{l}\text { Temperature corrected conduction } \\
\text { velocity }(\mathrm{m} / \mathrm{s})\end{array}$} \\
\hline & & Mean & Range & Mean & Range & Mean & Range \\
\hline \multicolumn{8}{|l|}{ SENSORY } \\
\hline Medial plantar & 21 & $1 \cdot 3$ & $0 \cdot 3-2 \cdot 8$ & $37 \cdot 7$ & $30 \cdot 5-47 \cdot 1$ & $43 \cdot 8$ & $34 \cdot 9-55 \cdot 9$ \\
\hline Sural (proximal segment) & 30 & $15 \cdot 4$ & $4 \cdot 0-41 \cdot 0$ & 44.9 & $39 \cdot 8-54 \cdot 0$ & $50 \cdot 2$ & $42 \cdot 8-59 \cdot 7$ \\
\hline Sural (distal segment) & 24 & $2 \cdot 5$ & $0 \cdot 5-6 \cdot 2$ & $33 \cdot 8$ & $23 \cdot 9-45 \cdot 4$ & $42 \cdot 1$ & $34 \cdot 4-49 \cdot 9$ \\
\hline $\begin{array}{l}\text { MOTOR } \\
\text { Posterior tibial }\end{array}$ & 30 & $11.4 \times 10^{3}$ & $\begin{array}{l}3.5 \times 10^{3}- \\
24.6 \times 10^{3}\end{array}$ & $48 \cdot 2$ & $42 \cdot 0-59 \cdot 0$ & $51 \cdot 7$ & $45 \cdot 0-59 \cdot 0$ \\
\hline
\end{tabular}


record in normal controls. ${ }^{15}$ Hence with present techniques the absence of the potential as an isolated finding cannot be considered pathological.

\section{Discussion}

The variable features of the tarsal tunnel syndrome ${ }^{21}$ and peripheral sensory neuropathy ${ }^{5}$ make their contribution to the foot pain of RD difficult to assess, especially as they may be easily masked by the other causes of pain in this condition. In the present study the frequency of both complications is much lower than other authors have reported.

Our finding of the tarsal tunnel syndrome in 4 patients $(13.3 \%)$ indicates that this condition may be an appreciable complication of the rheumatoid foot, particularly as this is a point prevalence study, and the overall frequency of extra-articular complications in RD, including the carpal tunnel syndrome, increases with the length of observation time ${ }^{22}$ However, the frequency is considerably less than that reported by Baylan et al., ${ }^{9}$ who failed to correct motor latency values for temperature. Their claim that this was unnecessary is at variance with standard neurophysiological practice ${ }^{1617} 192023$ and is incorrect for motor latencies of the medial and lateral plantar nerves, the very nerves being examined. ${ }^{16}{ }^{17} \mathrm{Had}$ we not made the necessary temperature corrections, our frequency for the tarsal tunnel syndrome would have reached $33 \%$, a figure comparable with theirs.

Only 2 patients $(6.6 \%)$ in this study showed electrical evidence of a distal sensory polyneuropathy, and one of these consumed more than $100 \mathrm{~g}$ of alcohol per day. No patient had a motor polyneuropathy. These results suggest that, while a peripheral sensory polyneuropathy may complicate $\mathrm{RD}$, it is uncommon.

We conclude that electrodiagnostic evidence of the tarsal tunnel syndrome occurs with an appreciable frequency in patients with RD involving the feet. However, these electrical abnormalities are mild, and the patients having them are clinically indistinguishable from other patients in the group. We also conclude that the distal sensory neuropathy in RD is uncommon.

We thank Dr J. Edmonds for permission to study his patients. We also thank the Department of Medical Illustration, Prince of Wales Hospital, for their assistance in the preparation of the figures.

\section{References}

1 Editorial. Rheumatoid neuropathy. Br Med J 1971; i: 516-7.

2 Hart F D, Golding J R, MacKenzie D H. Neuropathy in rheumatoid disease. Ann Rheum Dis 1957; 16: 471-80.

3 Nakano K K. The entrapment neuropathies of rheumatoid arthritis. Orthop Clin North Am 1975; 6: 837-60.

4 Nakano K K. Neurological complications of rheumatoid arthritis. Orthop Clin North Am 1975; 6: 861-80.

5 Barnes C G, Currey H L F. Carpal tunnel syndrome in rheumatoid arthritis. A clinical and electrodiagnostic study. Ann Rheum Dis 1967; 26: 226-33.

6 Lloyd K, Agrawal A. Tarsal-tunnel syndrome, a presenting feature of rheumatoid arthritis. Br Med J 1970; iii: 32.

7 Chater E H. Tarsal-tunnel syndrome in rheumatoid arthritis. $\mathrm{Br}$ Med J 1970; iii: 406.

8 Baylan S P, Paik S W, Barnert A L, Ko K H, Yu J, Persellin R H. Prevalence of the tarsal tunnel syndrome in rheumatoid arthritis. Rheumatol Rehabil 1981; 20: 148-50.

9 Amick L D. Muscle atrophy in rheumatoid arthritis. An electrodiagnostic study. Arthritis Rheum 1960; 3: 54-63.

10 Moritz U. Electromyographic studies in adult rheumatoid arthritis. Acta Rheum Scand 1963; 6 (suppl): 1-123.

11 Good A E, Christopher R P, Koepke G H, Bender L F, Tarter M E. Peripheral neuropathy associated with rheumatoid arthritis: a clinical and electrodiagnostic study of 70 consecutive patients. Ann Intern Med 1965; 63: 87-99.

12 Wasserman $R \mathbf{R}$, Oester $\mathrm{Y} T$, Oryshkevich $R \mathrm{~S}$, Montgomery M M, Poske R M, Ruksha A. Electromyographic, electrodiagnostic and motor nerve conduction observations in patients with rheumatoid arthritis. Arch Phys Med Rehabil 1968; 49: 90-5.

13 Frenay J, Goor C, Kievits J H, Endtz L J. Les neurodathies mixtes dans la polyarthrite chronique évolutive. Rev Neurol (Paris) 1976; 132: 63-71.

14 Burke D, Skuse N F, Lethlean A K. Sensory conduction of the sural nerve in polyneuropathy. J Neurol Neurosurg Psychiatry 1974; 37: 647-52.

15 Ropes M W, Bennett G A, Cobb S, Jacox R. 1958 Revision of diagnostic criteria for rheumatoid arthritis. Ann Rheum Dis 1959; 18: 49-53.

16 Johnson E W, Ortiz P R. Electrodiagnosis of tarsal tunnel syndrome. Arch Phys Med Rehabil 1966; 47: 776-80.

17 Fu R, De Lisa J A, Kraft G H. Motor nerve latencies through the tarsal tunnel in normal adult subjects: standard determinations corrected for temperature and distance. Arch Phys Med Rehabil 1980 ; 61: 243-8.

18 Guiloff R J, Sherratt R M. Sensory conduction in medial plantar nerve. J Neurol Neurosurg Psychiatry 1977; 40: 1168-81.

19 Bolton C F, Sawa G M, Carter K. The effects of temperature on human compound action potentials. J Neurol Neurosurg Psychiatry 1981; 41: 407-13.

20 Kaplan P E, Kernahan W T. Tarsal tunnel syndrome. An electrodiagnostic and surgical correlation. J Bone Joint Surg 1981; 63A: 96-9.

21 Mann R A. Tarsal tunnel syndrome. Orthop Clin North Am 1974; 5: 109-15.

22 Fleming A, Dodman S, Crown J M, Corbett M. Extra-articular features in early rheumatoid disease. Br Med J 1976; i: 1241-3.

23 Buchthal F, Rosenfalck A. Evoked action potentials and conduction velocity in human sensory nerves. Brain Res 1966; 3: 1-122. 